\title{
Impact of unusually clear weather on United States daily temperature range following 9/11/2001
}

\author{
Adam J. Kalkstein*, Robert C. Balling Jr \\ Department of Geography, Arizona State University, Tempe, Arizona 85287-0104, USA
}

\begin{abstract}
Several investigators have suggested that the airline shutdown following the 9/11 terrorist attacks led to a reduction of jet contrails and an increase in the diurnal temperature range (DTR) across the US. Here, we use an air-mass approach to control for weather conditions across the country following $9 / 11$ in order to more accurately assess the observed patterns in the temperature range. We indeed find a higher-than-average DTR shortly after the attacks, but we find that the unusually clear weather across the US more than accounts for the observed DTR.
\end{abstract}

KEY WORDS: Jet contrails · Diurnal temperature range $\cdot$ Air masses

Resale or republication not permitted without written consent of the publisher

\section{INTRODUCTION}

Contrails are formed from the exhaust of highaltitude jets, and under certain conditions, they have been documented to last for hours, fanning out in various directions (Minnis et al. 2002). It has been suggested that contrails act similarly to natural cirrus clouds, altering the radiation budget at the surface by absorbing longwave radiation at night and reflecting more shortwave radiation into space throughout the day (Sassen 1997, Penner et al. 1999). As a result, it is possible that the diurnal temperature range (DTR), daily maximum-minus-minimum temperature, is affected by the cirruslike properties of contrails. Recently, scientists have attempted to estimate the radiative impacts of jet contrails using both computer models and satellite data (Palikonda et al. 1999, Penner et al. 1999, Minnis et al. 2001a,b, Marquart \& Mayer 2002, Ponater et al. 2002), but results of the radiative forcing have varied considerably from study to study.

The airline shutdown following the terrorist attacks on $9 / 11$ provided scientists with a unique opportunity to determine what impacts jet contrails have on regional climate. Travis et al. (2002) suggested that the lack of contrails in the $3 \mathrm{~d}$ following 9/11 produced the largest increase in DTR for those dates in the past $30 \mathrm{yr}$ based on records from approximately 4000 stations throughout the conterminous US. They argued that the absence of contrails could increase incoming solar and outgoing infrared radiation, thus allowing for an increase in the daily temperature range.

In this investigation, we revisit the issue of DTR following the 9/11 attacks, but we use an air-mass approach to control for weather conditions across the country. Pictures taken shortly after the attacks show clear skies in New York, Washington, and Pennsylvania, and these transparent conditions were present across a large portion of America on 11 and 12 September 2001 (Fig. 1), while the days that followed showed increasing cloudiness. It is possible that the relatively transparent conditions for a few days after the attacks produced the observed jump in the DTR, not the lack of contrails.

\section{DATA}

We assembled 2 basic datasets for our analyses of near-surface air temperature and air-mass patterns:

(1) The daily air-mass calendar, developed by Sheridan (2002), was used to examine 120 stations in the conterminous US. The stations were selected based upon data completeness over the 1971 to 2001 time period selected for this study. For each station and each day from 4 to 21 September, 1971 to 2001, the 'spatial synoptic classification' (SSC) examined numer- 


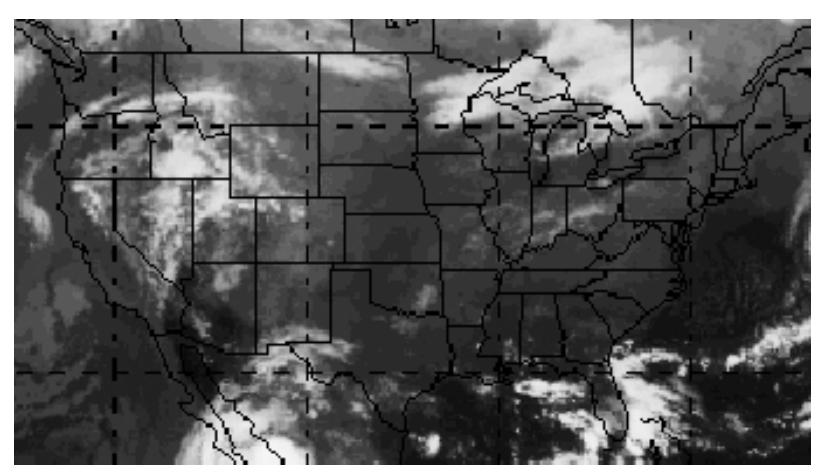

Fig. 1. Satellite-based infrared image (GEOS NH Infrared from UNISYS) showing mostly clear conditions across the US on 12 September 2001

ous meteorological conditions such as temperature, humidity, cloud cover, wind speed and direction to accurately place each day into 1 of 7 potential air masses: dry tropical, dry moderate, dry polar, moist tropical, moist moderate, moist polar, or transition. An air-mass approach to any assessment of a regional DTR is beneficial, since it takes into account the entire 'umbrella' of air present over a region, rather than just individual meteorological conditions. It is important to note that, although the air-mass classification does take cloud cover into account, it would be virtually unaffected by jet contrails, since the classification system assesses many meteorological variables, and a small increase or decrease in contrail-related cloud cover would be negligible. In addition, we used a nearest-neighbor analysis (Clark \& Evans 1954) and found the network of stations to be randomly to uniformly distributed in space with no regional bias.

(2) Actual daily temperature range was calculated for each day at each station by subtracting the daily minimum temperature from the daily maximum temperature. Unlike the Travis et al. (2002) study which calculated daily temperature range by examining the maximum temperature on one day and the minimum temperature on the following day, we were forced to use both maximum and minimum temperatures from the same day. The SSC classifies 1 air mass per day at each station, and if we examined temperatures from 2 different days, it is possible that they would be within different air-mass types, making an air-mass-based approach on this study impossible.

\section{ANALYSES AND RESULTS}

To better examine what impact jet contrails (or lack thereof) have on climate, it is beneficial to control for the air-mass conditions present across the country to determine what the temperature range should have been for the $4 \mathrm{~d}$ period (11-14 September 2001) based upon similar synoptic conditions in the past. Using the air-mass calendar and temperature data, we calculated the average daily temperature range for each air mass at each station based on data from 4 to 21 September over 1971-2001. Thus, we were able to 'predict' what the temperature range should have been at each station from 11 to 14 September 2001 based upon the air mass present. The predicted values for each station can be averaged across the US and then compared to the observed temperature ranges calculated from the maximum and minimum temperature data for the dates following the attacks. Thus, each day from 4 to 21 September, 1971-2001, has both a predicted temperature range value and an observed temperature range value. It is important to note that the average predicted values produced a small but consistent bias by under-predicting the highest temperature range days and over-predicting the lowest, although we did not correct for this small effect. As seen in Fig. 2, the nationwide predicted and observed DTR values have a correlation coefficient of 0.91 and a mean absolute difference between them of $0.44^{\circ} \mathrm{C}$.

To better assess the effectiveness of air-mass type to accurately predict daily temperature range on a station-by-station basis, 6 stations were examined: Phoenix, AZ; Miami, FL; Philadelphia, PA; Chicago, IL; St. Louis, MO; and Seattle, WA. The predicted temperature range was compared to the actual temperature range for each day at each of the 6 stations. As expected, the air-mass-based approach predicted the DTR more accurately at stations with moderate climates, such as Miami. However, the system was slightly less effective for stations that exhibit higher fluctuations of the DTR on a day-to-day basis, such as Chicago and St. Louis. Concurrently, the difference between the predicted temperature range values and the actual values was examined for the 6 stations. The average difference between actual and predicted temperature range for Miami was $1.20^{\circ} \mathrm{C}$, with a standard deviation of $0.91^{\circ} \mathrm{C}$. However, for Chicago and St. Louis, the average differences were 2.21 and $1.90^{\circ} \mathrm{C}$, respectively, with standard deviations of 1.63 and $1.50^{\circ} \mathrm{C}$. It is important to note that, although the airmass-based prediction of the DTR was only moderately effective for individual stations, it was highly effective for the country as a whole as seen in Fig. 2.

Next, we examined the air masses present across the country for the $4 \mathrm{~d}$ period from 11 to 14 September 2001. On 11 September, the country was experiencing unusually clear, cool, and dry conditions with dry polar air masses reported at $75 \%$ of the stations. September 12 had similar conditions, with dry polar air masses reported at $70 \%$ of the stations. September 13 was a day of transition across the country as the unusually 


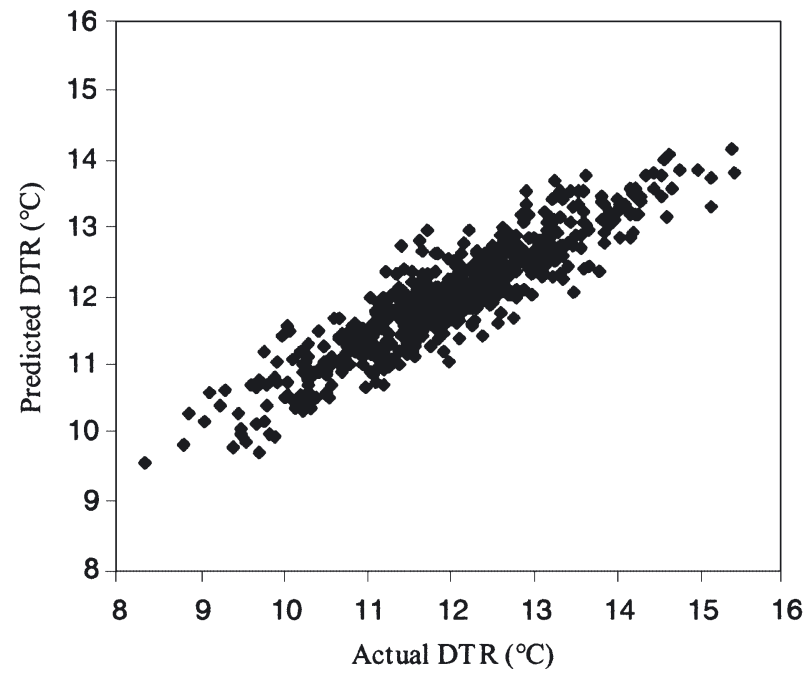

Fig. 2. Scattergram of the nationwide observed and 'predicted' diurnal temperature range (DTR) averages for the US from 4 to 21 September 1971-2001

clear pattern began to retreat, bringing in cloudier, more humid air. As a result, $42 \%$ of the stations reported either moist tropical, moist moderate, or moist polar air masses, while $46 \%$ of the stations reported dry polar. Concurrently, a sharp decrease in average daily temperature range was observed (Fig. 3). By September 14, much of the country was shrouded in clouds, with $44 \%$ of the stations reporting moist air masses and only $27 \%$ reporting dry polar air. This shift in air-mass pattern is illustrated in the unusually high average daily temperature range on September 11 and 12 with declining temperature ranges thereafter (Fig. 3).

We determined that the average DTR for the US was $12.00^{\circ} \mathrm{C}$ for September 4 to 21 over 1971-2001, with a standard deviation of $1.20^{\circ} \mathrm{C}$. As seen in Fig. 3 and quite consistent with Travis et al. (2002), the observed DTR was unusually high on 11 and 12 September 2001, averaging $13.24^{\circ} \mathrm{C}$. Our air-mass classification system produced a predicted value of the DTR of $13.56^{\circ} \mathrm{C}$ for those 2 days, which is especially surprising considering the prediction system tended to under-predict days with unusually high DTR. Conditions became somewhat cloudier on 13 and 14 September 2001, and the observed temperature range fell accordingly to an average of $10.96^{\circ} \mathrm{C}$. However, our air-mass classification system 'predicted' an average temperature range of $11.81^{\circ} \mathrm{C}$ for those 2 days, indicating that the observed values were substantially less than the predicted values. Based on the $4 \mathrm{~d}$ period 11 to 14 September 2001, when air traffic was effectively halted in North America (limited service was available on 14 September), the observed DTR was $12.10^{\circ} \mathrm{C}$, which was only slightly above the average value for that time of year. The 'predicted' value for that same time period was $12.68^{\circ} \mathrm{C}$, showing that overall, the unusually high observed DTR value was likely not increased by the absence of contrails. We recognize that our model over-predicted DTR on all 4 days of interest in this study. However, 4 consecutive days of over-prediction or under-prediction is not particularly unusual over 1971-2001. It is important to note that we found no significant $\left(\mathrm{r}^{2}=0.002\right)$ trend in the DTR time series that might have biased our study given that 2001 occurs at the end of the study period.

\section{CONCLUSIONS}

Travis et al. (2002) produced a calculation suggesting that the lack of contrails during the airline shutdown following the attacks of 11 September 2001 resulted in a substantial rise in the diurnal temperature range across the US. The obvious interpretation is that contrails have a strong impact on surface temperature patterns at the regional scale. However, Travis et al. (2002) did not control for the air-mass conditions across the US that may have been responsible for the observed increase in diurnal temperature range immediately following the attacks.

By controlling for the air masses present across the US, we found that the unusual temperatures on 11 and 12 September were a result of a particularly clear weather pattern, not a lack of jet contrails. Furthermore, the average diurnal temperature range for 11 to

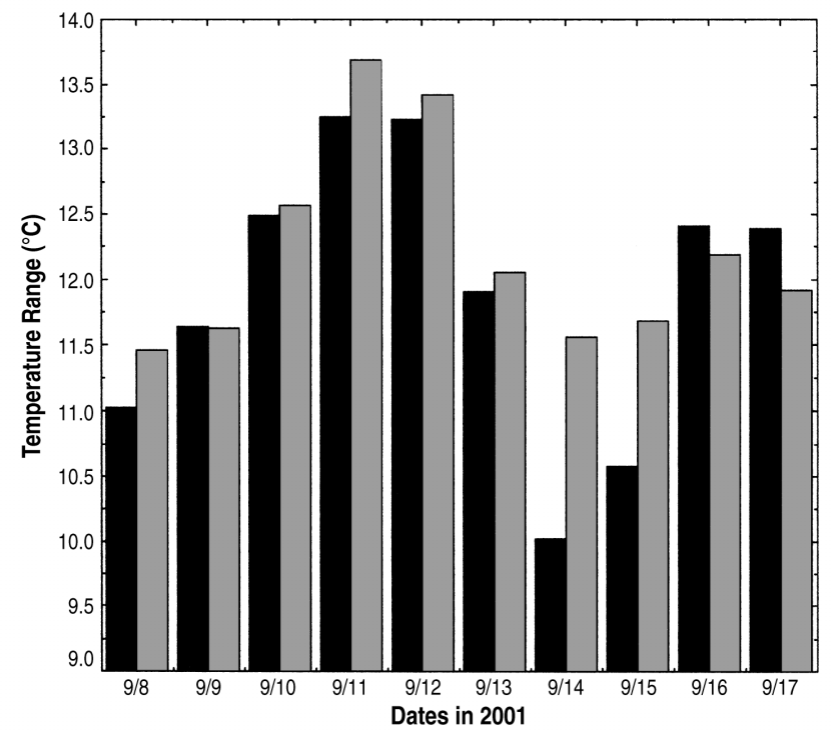

Fig. 3. Average US diurnal temperature range (black bars) versus 'predicted' values given air-mass pattern (gray bars) 
14 September 2001 was only slightly above average, but well below what should have occurred based upon air masses present across the country. There is no doubt that contrails have some effect on the regional, hemispheric, and global climate system (Penner et al. 1999), but we conclude that the magnitude of this effect was overestimated by the Travis et al. (2002) study.

\section{LITERATURE CITED}

Clark PJ, Evans FC (1954) Distance to nearest neighbor as a measure of spatial relationships in populations. Ecology 35:445-453

Marquart S, Mayer B (2002) Towards a reliable GCM estimation of contrail radiative forcing. Geophys Res Lett 29: 10.1029/2001GL014075

Minnis P, Ayers JK, Palikonda R, Doelling DR, Schumann U, Gierens K (2001a) Changes in cirrus cloudiness and their relationship to contrails. In: AMS 12th Symposium on Global Change Studies and Climate Variations, Albuquerque, NM, January 15-19, p 239-242

Minnis P, Palikondra R, Ayers JK, Duda DP, Costulis KP (2001b) Cirrus, contrails, and radiative forcing over the USA: their relationships to air traffic and upper tropo-

Editorial responsibility: Robert Davis,

Charlottesville, Virginia, USA spheric conditions. In: Schumann U (ed) Aviation aerosols, contrails, and cirrus clouds (A2C3), European Commission, Brussels, p 193-196

Minnis P, Nguyen L, Duda DP, Palikonda R (2002) Spreading of isolated contrails during the 2001 air traffic shutdown. In: AMS 10th Conference on Aviation, Range, and Aerospace Meteorology, Portland, OR, May 13-16

Palikonda R, Minnis P, Doelling DR, Heck PW, Duda DP, Mannstein H, Schumann U (1999) Potential radiative impact of contrail coverage over continental USA estimated from AVHRR data. In: AMS 10th Conference on Atmospheric Radiation, Madison, WI, June 28-July 2, p 181-184

Penner JE, Lister DH, Griggs DJ, Dokken DJ, McFarland M (eds) (1999) Aviation and the global atmosphere. Cambridge University Press, Cambridge

Ponater MS, Marquart S, Sausen R (2002) Contrails in a comprehensive global climate model: parameterization and radiative forcing results. J Geophys Res 107(D13):10.1029/ 2001JD000429

Sassen K (1997) Contrail-cirrus and their potential for regional climate change. Bull Am Meteorol Soc 78: 1885-1903

Sheridan SC (2002) The redevelopment of a weather-type classification scheme for North America. Int J Climatol 22: $51-68$

Travis DJ, Carleton AM, Lauritsen RG (2002) Contrails reduce daily temperature range. Nature 418:601

Submitted: May 14, 2003; Accepted: February 20, 2004

Proofs received from author(s): April 2, 2004 